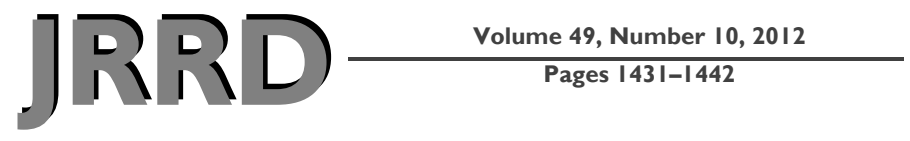

\title{
Beyond componentry: How principles of motor learning can enhance locomotor rehabilitation of individuals with lower limb loss-A review
}

\author{
Andrew Sawers, CPO, PhD; ${ }^{1-2 *}$ Michael E. Hahn, PhD; ${ }^{1,3}$ Valerie E. Kelly, PT, PhD; ${ }^{2}$ Joseph M. Czerniecki, \\ MD; ${ }^{1-2}$ Deborah Kartin, PT, $\mathbf{P h D}^{\mathbf{2}}$ \\ ${ }^{1}$ Department of Veterans Affairs (VA) Rehabilitation Research and Development Center of Excellence for Limb Loss \\ Prevention and Prosthetic Engineering, VA Puget Sound, Seattle, WA; Departments of ${ }^{2}$ Rehabilitation Medicine and \\ ${ }^{3}$ Mechanical Engineering, University of Washington, Seattle, WA
}

\begin{abstract}
Relatively little attention has been given to the use of well-established motor learning strategies to enable individuals with lower limb loss to effectively and safely learn to walk with their prostheses in the home and community. Traditionally, such outcomes have been pursued by focusing on the design and function of a patient's prosthesis, rather than on how he or she should learn to use it. The use of motor learning strategies may enhance physical rehabilitation outcomes among individuals with lower limb loss. This review explores these motor learning strategies and ways in which they can be applied to the physical rehabilitation of individuals with lower limb loss and highlights some of the challenges to their implementation, as well as unanswered research questions.
\end{abstract}

Key words: amputee, artificial limb, gait, learning, limb loss, locomotion, practice, prosthesis, rehabilitation, training.

\section{INTRODUCTION}

In the physical rehabilitation of individuals with lower limb loss, relatively little attention has been given to the use of well-established motor learning strategies and how such strategies can be implemented before, during, and after physical practice to enable individuals with lower limb loss to effectively and safely use their prostheses. This review explores the potential application of motor learning principles to the physical rehabilitation of individuals with lower limb loss and suggests future research directions in this area.
A key component of physical rehabilitation is relearning how to move [1] in order to perform functional tasks. This can be accomplished through the recovery of previously learned movement strategies or the acquisition of new compensatory movement strategies [2]. This process assumes that following an acute injury or the onset of longterm impairment, deliberate practice combined with appropriate therapeutic, pharmacological, or technological innovations will lead to a relatively permanent acquisition, improvement, or return of motor function [3]. Therefore, motor learning plays a central role in achieving rehabilitation goals.

"Motor learning" can be defined as the acquisition or modification of skilled movements. It consists of a series of distinct yet overlapping stages that include (1) repeated sensorimotor adaptation to facilitate motor skill acquisition [4], (2) motor memory consolidation [5-6] to store the acquired motor skill in a robust and permanent state for later use, and (3) the formulation of decision-making rules [7] to facilitate future performance by enabling the selection of the optimal

\footnotetext{
Abbreviation: $\mathrm{KR}=$ knowledge of results.

*Address all correspondence to Andrew Sawers, CPO, PhD; The Wallace H. Coulter Department of Biomedical Engineering, Emory University and the Georgia Institute of Technology, 313 Ferst Dr, Atlanta, GA 30332. Email: andrew.b.sawers@emory.edu http://dx.doi.org/10.1682/JRRD.2011.12.0235
} 
movement pattern from those that are available. Together, these steps lead to a relatively permanent change in the capacity for producing a skilled action [8] and provide a solution to a given task [9]. The extent to which motor learning has occurred must be inferred from either retention, the durability or recall of the acquired skill over time, or transfer and generalization, the degree to which the newly acquired skill can be produced using a different device, in a new environment, or with different forms of movement from which it was originally practiced [10].

The physical rehabilitation of an individual with lower limb loss has traditionally been guided by a devicedriven paradigm [11]. To overcome physical challenges that are commonly attributed to individuals with lower limb loss, such as balance control [12], proximal and contralateral joint compensations [13], and difficulty adapting to uneven terrain [14-15], clinical practice has historically focused on the design and function of the prosthesis, rather than on learning how to use it. Compared with other domains of physical rehabilitation [1617], the field of prosthetics has paid little attention to the translation of well-established motor learning strategies [18-20]. Instead, physical rehabilitation for individuals with lower limb loss has traditionally focused on what tasks to practice [21-24] and which strength and conditioning exercises to perform [25-29], rather than on how motor learning principles should be applied to the structure and organization of practice in order to most efficiently and effectively learn those tasks. The current state of prosthetic research also reflects this priority. Much of the research efforts appear to be directed toward the development of advanced prosthetic technology, novel surgical procedures, and control or feedback mechanisms to run biomimetic prostheses. While progress in those areas of research is of unquestionable value, the field of prosthetics would also benefit from the concurrent exploration of motor learning strategies specific to the needs of individuals with lower limb loss in order to maximize utilization of these technologies. Currently, no guidelines exist in the United States for the continuum of care for individuals with lower limb loss [30], including how patients should be taught to use their prostheses.

Knowledge of patient-based training strategies that promote motor learning is necessary for all members of the physical rehabilitation team involved in the care of individuals with lower limb loss. Despite limited use in the physical rehabilitation of individuals with lower limb loss, these strategies have the potential to improve locomotor rehabilitation and thereby improve functional mobility regardless of prosthetic design. The examination of motor learning strategies is timely and highly relevant given the accelerated rate of technological innovation in the field, yet such strategies are commonly ignored when that technology is integrated into clinical practice [31]. This has resulted in a functional knowledge gap concerning how individuals with lower limb loss should learn to use their prostheses.

The primary objective of this article is to address an initial portion of this knowledge gap by reviewing motor learning principles known to enhance motor learning among adults who are unimpaired and examine how these principles might be applied during physical rehabilitation to enhance the functional mobility of individuals with lower limb loss. A secondary objective is to highlight potential areas of future research.

\section{MOTOR LEARNING STRATEGIES AND THEIR POTENTIAL APPLICATION TO PHYSICAL REHABILITATION OF INDIVIDUALS WITH LOWER LIMB LOSS}

The power law of practice [32-33] is perhaps the most fundamental training principle in motor learning; all other things being equal, the degree of performance improvement depends on the amount of practice [34]. However, the application of such a principle to the physical rehabilitation of individuals with lower limb loss is often not practical. The amount of physical training is typically limited by time, financial, personnel, and safety considerations, as well as equipment availability and physical limitations due to various comorbidities. Fortunately, these limitations may be addressed by implementing a range of other training strategies before, during, and after deliberate physical practice in order to maximize training efficiency and effectiveness.

\section{Motor Learning Training Strategies Utilized Before Practice}

Research on adults without impairments has taught us that goal setting, observational training, and mental practice can all enhance motor learning when used before engaging in deliberate physical practice. For learning sport and exercise tasks such as basketball, bowling, and weight lifting, simple "do your best" goals are not as effective as individualized short- and long-term goals of 
moderate difficulty [35]. Such goal-setting activities are thought to enhance motor learning because they serve to (1) focus performance during practice, (2) regulate effort directed toward performance, (3) help maintain vigilance in reaching goals, and (4) act as a reference against which achievement can be measured [36]. While the influence of goal setting on the locomotor rehabilitation of individuals with lower limb loss remains unknown, it is reasonable to expect that it would lead to improved locomotor function given the success with sports-related tasks. Following a thorough patient evaluation and before the delivery of the prosthesis, a series of specific, individualized, short- and long-term goals could be developed collaboratively by the patient, his or her family, and the rehabilitation team. These goals may include a number of prosthetic-specific activities for which an increasing level of independence is achieved in a variety of environments including the hospital, the primary residence, and the community. Such goalsetting activities for an individual with lower limb loss should focus on activities that are salient to the patient. These may include short-term goals such as the ability to don his or her prosthesis with progressively less assistance, as well as more long-term goals such as navigating increasingly challenging terrain in varying environmental conditions (e.g., low light, inclement weather) in and around his or her community. This patient-centered approach to goal-setting may have a positive effect on motivating the patient and retaining his or her attention during training. A number of challenges to goal setting can also be anticipated. Specifically, a patient's lack of expertise in the field and overly ambitious expectations for his or her recovery have been cited as potential issues to consider when attempting to include patients in the process [37]. Also, any additional time required during clinical visits would have to be accounted for [38].

While not as effective as physical practice, both observational training [39], where the learner observes a model performing the skill he or she is trying to learn, and mental practice [40], where performance of a skill is imagined or visualized without overt physical movement, have been shown to be more effective in learning motor skills than no practice at all. Among adults who are unimpaired, retention of a variety of motor skills, such as dancing [41] and surgical procedures [42], has been found to improve when observational practice is used before physical practice regardless of whether the learner observes a novice or expert model [43-44]. Engaging in mental practice prior to physical practice has also been shown to result in notable improvements in the performance of motor tasks [34]. The success of observational training and mental practice may lie in the fact that similar regions of the brain become activated during action production and observation [45], as well as during action production and imagination [46-47]. Mental practice has also been found to elicit electromyographic responses that are scaled down versions of those generated during actual movement production [48].

Given these improvements in motor performance among adults without impairments, observational training and mental practice may be useful during the physical rehabilitation of an individual with lower limb loss where the amount of physical practice is often limited by fatigue or the physical capacity of the patient. Despite a slight decline in the vividness and time required to imagine movements with the residual limb [49], individuals with lower limb loss retain the ability to activate the appropriate regions of the sensorimotor cortex when imagining movements of the missing limb segment(s) and the residuum [50]. Therefore, the use of mental practice with motor imagery seems plausible and could likely be used to assist in learning a variety of motor skills with a prosthesis. For example, when training an individual with lower limb loss to rise from a chair while wearing his or her prosthesis, clinicians may consider instructing the individual to visualize performing the sit-to-stand task from a first-person perspective, actually visualizing himor herself rising from the chair. This form of imagery versus that of a third-person perspective, visualizing someone else rising from a chair, has been shown to be more effective for learning new motor skills that rely on coordination and timing [51]. Mental practice faces several challenges that may limit its implementation among individuals with lower limb loss. These include whether patients should be passively engaged by listening to descriptions of movement tasks or more actively engaged by directly imagining the movements themselves. In addition, the degree of clinical supervision necessary is a consideration [52], as is how progress achieved via mental practice should be monitored [53]. Further, who are the most appropriate individuals to benefit from the use of mental practice is unclear. All these considerations represent potential areas of future research.

Observational training [54-55] and mental practice [56-57] are most effective when interspersed with physical practice. Combining physical practice with observational training is referred to as dyad training. In dyad 
training, participants alternate between observing the other learner and physically practicing the task themselves. Despite undertaking only half the physical practice over the same time period, dyad training has been shown to result in equivalent or superior motor learning to that following physical practice alone [58-60]. Upon delivery of the prosthesis, clinicians might consider initiating dyad training. Patients could be paired with one other based on similar abilities and goals in order to learn a variety of motor skills with and without their prostheses. The use of dyad training naturally incorporates rest periods, and to ensure maximum benefit from these rest periods, a portion of them could be allocated to observational training. This would allow each patient to use his or her partner as the model they observe (novice model) and intersperse observational training with physical practice, a procedure shown to increase motor learning $[43,56,61]$. Alternating physical practice with less strenuous forms of training may also serve to increase the total volume of training performed by individuals with lower limb loss for whom the amount of physical practice is often limited by fatigue or physical capacity. The application of dyad training to the physical rehabilitation of individuals with lower limb loss remains limited because of a lack of understanding regarding the specific criteria, physical and otherwise (e.g., cognitive function), upon which patients should be paired. It also remains unknown whether similar training could be accomplished in larger groups. Administrative considerations such as billing practices and privacy concerns (i.e., HIPAA [The Health Information Portability and Accountability Act of 1996]) may also need to be addressed.

\section{Motor Learning Training Strategies Utilized During Practice}

Once the learner is physically engaged in deliberate practice, the manner in which training is organized, the amount of physical guidance provided, and the focus of the learner's attention can all influence how well a motor skill is learned. Physical practice can be organized in a number of ways that differ from massed practice, where practice time vastly exceeds rest time. Among adults without impairments, the use of distributed practice to introduce frequent and longer rest periods between repetitions improves performance of balance tasks and novel upper-limb tasks during initial training [62] and subsequent performance [63-64]. Distributed practice has been found to be more effective for learning continuous tasks such as walking, which have no distinct beginning or end, while massed practice appears to be more effective for learning discrete tasks, which have a definitive beginning and end [65]. This may be an important distinction when designing a physical rehabilitation protocol, and as such, clinicians should consider how distributed versus massed practice may be best suited for different motor tasks. For example, if the function of a transfemoral prosthesis were to be altered through modifications to the alignment and settings of the knee unit or replacement of the knee with an alternative design, clinicians may choose to implement distributed practice when training the patient to walk with the new or altered prosthesis. Alternatively, if the patient is learning a discrete motor skill, such as rolling on a gel liner, greater learning may be achieved using massed practice.

Using variable practice, where skills that are similar to and surround the goal task are performed, rather than constant practice, where merely the goal task itself is trained, leads to improvements in the retention and transfer of novel upper-limb throwing tasks [66], even though performance during initial training may be worse [67]. Variable practice has also been found to improve the transfer of motor skills to contexts beyond those originally practiced $[66,68]$, an important criterion for motor learning and physical rehabilitation. Organizing practice in a variable fashion may also lead to what has been termed "learning to learn" [10]. Through acquisition of multiple motor skills, faster learning occurs on other unrelated skills. Rather than learning a particular skill, individuals are learning to be adaptable, increasing their ability to recognize patterns, detect errors, and make corrections [10]. While no published research has assessed the feasibility and efficacy of applying variable versus constant practice to the rehabilitation of individuals with lower limb loss, their incorporation as part of a physical rehabilitation protocol may be of benefit. For example, during physical practice of prosthetic-related motor skills, such as sit-to-stand activities or ambulation over different terrains, patients could be encouraged to perform variations of the same skill. Clinicians may consider having patients practice sit-to-stand and stand-to-sit activities from different types of chairs (e.g., arm rests, no arms rests) as well as chairs of varying heights. Additionally, clinicians could consider using various types of surfaces (e.g., carpeting, artificial grass) during gait training to create a more variable practice structure. Clinicians could also make use of treadmills, which allow for level, 
incline, and decline walking to take advantage of the established benefits of variable practice during gait retraining.

Engaging in random practice, where several different motor skills are practiced in a random order across trials, rather than blocked practice, where each skill is practiced repeatedly in a group of trials, increases retention and transfer of those motor skills despite the degradation of performance during initial training [69-70]. Rather than having patients practice one motor skill at a time, clinicians may consider having patients alternate between practicing donning their prostheses, walking with their prostheses, and transferring with their prostheses in a random order so as to take advantage of the established benefits of random practice [70]. However, when the patient has little to no experience using a prosthesis, he or she may benefit from blocked practice during initial training, progressing to random practice as his or her skill level increases.

One can choose to practice each component or movement of a motor skill separately via part-practice or practice the skill in its entirety with whole-practice. Partpractice is considered useful for reducing the burden of repeatedly practicing the parts of a skill that are easier by focusing on the more difficult parts or for learning skills that are very complex and difficult to initially perform as a whole [34]. Research in adults without impairments indicates that serial tasks, those composed of distinct subtasks, such as donning a prosthesis, tend to be learned more effectively using part-practice [71], while continuous and discrete tasks, such as walking and rolling on a gel liner, respectively, are learned much better using whole practice [72]. Those prosthetic skills that are continuous, such as walking, should be practiced as whole skills, whereas those skills that are serial in nature, such as donning a prosthesis, should initially be broken down into their constituent parts and practiced separately before being reassembled and practiced in their entirety.

Physical guidance involves the application of corrective forces to reduce movement errors during practice and is often advocated to improve initial performance. However, such a strategy has been found to hinder retention of relatively simple locomotor skills [73-74] among adults without impairments, thus raising questions about its use as a learning aid. Nonetheless, some physical guidance may be beneficial with more challenging or complex skills $[73,75]$, when the skill is unfamiliar, or when preventing injury or reducing fear associated with performing the skill is of primary concern, all scenarios that are common to the physical rehabilitation of individuals with lower limb loss. Therefore, despite the lack of support for using physical guidance to improve motor learning [73], it may be justified during locomotor rehabilitation of individuals with lower limb loss given their high frequency of falls during rehabilitation (i.e., 20\%) [76], the fear of falling expressed [12], and the initial slow pace and complexity of walking with a prosthesis.

Physical guidance while learning to walk with a prosthesis may help to maintain patient safety and build patient confidence during training. Physical guidance may prove useful not only during the initial rehabilitation of individuals with lower limb loss, but also when substantial changes are made to the design of their prostheses. For example, if the swing phase characteristics of a prosthetic knee are altered, clinicians may want to guide terminal swing to ensure appropriate foot placement at heel-strike. If the medial-lateral alignment of the prosthetic foot is altered, clinicians may want to provide some initial assistance to frontal plane stability during single-limb stance. In either case, as confidence, balance control, and skill level increase, the amount of physical guidance that is provided should be gradually reduced to prevent dependence.

An individual's focus of attention during training also has implications for motor learning. During physical practice, adopting an external focus, where attention is directed toward the task goal, rather than an internal focus, where attention is directed toward specific body movements [77], has been demonstrated to enhance learning of a variety of sports skills [78-80] and balance tasks [81] among adults without impairments. Such outcomes are believed to arise from the fact that an external focus promotes the utilization of unconscious processes, while an internal focus produces a more conscious type of control that disrupts automatic control processes [82]. In light of these outcomes, clinicians may want to consider instructing individuals with lower limb loss to adopt an external focus (e.g., focusing on their position relative to others) when physically practicing balance-related activities such as standing in a crowded space or entering and exiting and automobile.

Perhaps the greatest barrier to implementing many of these "during-practice" training strategies is understanding when and how to apply them so as to ensure the appropriate level of practice difficulty to facilitate motor learning. For example, during variable practice, when should the number of task variations be increased or 
decreased? During distributed practice, when should the duration and timing of rest periods be adjusted? During part-practice, when and how should the separate parts of each skill be recombined? Lastly, regardless of practice organization, when should physical guidance be increased or phased out? The lack of any established motor or neurophysiological milestones upon which such decisions could be based leaves the specific application of these "during-practice" training strategies to individuals with lower limb loss open to the subjective assessment of the clinician and subject to future research.

\section{Motor Learning Training Strategies Utilized After Practice}

Augmented feedback provides the learner with information about what was done during practice [34]. It is considered one of the most influential variables affecting the learning of motor skills [83-84] because it provides additional information regarding performance that would otherwise not be available to the learner. Augmented feedback can consist of information about goal achievement, referred to as "knowledge of results" (KR), or the nature of the movement itself, referred to as "knowledge of performance."

Among adults without impairments, KR generally increases learning of novel motor skills when it is provided at a reduced frequency (e.g., $50 \%$ vs $100 \%$ of trials) during variable practice of relatively simple skills [85] and at a greater frequency for constant practice of more complex skills [86]. Motor learning is also improved when KR is delivered with a slight delay following completion of the movement under evaluation in order to allow the learner sufficient time to first evaluate his or her movement and generate his or her error estimates [87]. Providing KR in a summary form [88-89] about a series of trials, rather than each individual trial, also improves motor learning. The optimal number of trials to be summarized when providing KR appears to depend on the interaction between task difficulty and experience of the learner [88]. Relatively long feedback summaries, where KR covers many trials at once, appear to improve learning for novice and experienced learners attempting simple tasks, as well as for experienced learners attempting more challenging tasks. For novices learning more challenging tasks, single-trial $\mathrm{KR}$ appears to facilitate superior motor learning $[88,90]$.

While limited research has examined the use of augmented feedback among individuals with lower limb loss
[19], its use during locomotor rehabilitation is worthy of further consideration. During initial gait training, individuals with lower limb loss may benefit from receiving KR at a relatively high frequency $(>50 \%)$ because of the complexity and novelty of learning prosthetic skills and their inexperience walking with a prosthesis [86]. For example, clinicians could provide an initially high rate of feedback regarding aspects of gait such as foot placement, knee angle, or hip extension that act to ensure adequate knee stability during stance phase for individuals with transfemoral limb loss. Much like the provision of physical guidance, as skill level and confidence increase, the frequency of feedback could be gradually reduced as to prevent patients from becoming reliant on it. The delivery of feedback should be delayed [87] and the content prescriptive. Rather than simply describing what was done incorrectly, clinicians should provide suggestions on ways to correct the movement or movement outcome. During initial learning, it may serve the patient well to provide feedback for each trial, graduating to summary forms of feedback at a lower frequency as skill level improves [86]. Additionally, rather than relying solely on the clinician to provide feedback, future prosthetic designs may incorporate the necessary technology to collect, process, and analyze data such that augmented feedback can be obtained directly from the prosthesis. One of the potential challenges to the utilization of augmented feedback in the rehabilitation of individuals with lower limb loss is determining when the frequency, content, and/or timing of the feedback should be altered. Furthermore, our ability to personalize or select appropriate initial feedback settings such as frequency, timing, and content is limited by our understanding of how the difficulty of different motor tasks varies among patients according to age, etiology, or time since limb loss.

\section{CONCLUSIONS}

Considerable research has gone into identifying how various training strategies can be applied before, during, and after deliberate practice to enhance motor learning among individuals without locomotor impairments. However, many questions remain regarding their use in the rehabilitation of individuals with lower limb loss. A central issue that is yet unresolved and may delay clinically relevant research is the extent to which improvement in motor performance among individuals with 
lower limb loss can be attributed to specific training strategies versus spontaneous or natural recovery. Among individuals with lower limb loss, neither the timeline nor specific events that constitute the natural course of recovery following lower limb loss have been well studied. Future research in these areas would afford clinicians and researchers alike a better understanding of when interventions should be applied and assist in discriminating the benefits of the training strategy from those of spontaneous biological processes.

In addition to the "how" (i.e., which motor learning strategies should be utilized), future research should also address the "who" (i.e., which patients respond best to which motor learning strategies) and the "what" (i.e., which constructs or dimensions of mobility should be emphasized during training). Understanding the way that different patient characteristics, such as time since limb loss, etiology of limb loss, and level of limb loss, affect the various motor learning strategies will be crucial to their successful translation into clinical practice. Furthermore, the influence of commonly encountered "stressors," such as pain, anxiety, and fatigue, on the various motor learning strategies requires further clarification before these motor learning strategies can be applied to clinical practice. Further research is also needed to identify specific dimensions of mobility [91] that hold salience for individuals with lower limb loss (e.g., balance control) and provide the necessary requirements for successful locomotion [92]. This will be essential to ensuring that any motor learning strategy contributes in a positive manner to the physical rehabilitation of individuals with lower limb loss.

Research into the application of motor learning strategies may also serve to broaden the number of individuals with lower limb loss who are considered candidates for advanced prosthetic technology beyond the small percentage who make up the most active portion of the population. As it currently stands, prescription criteria limit access to advanced prosthetic technology to all but the most active patients. It is thought that those individuals who are less active are unable to learn to use such technology effectively and do not require, nor would they benefit from, many of the features provided by such technology. The identification of effective motor learning strategies may enable these individuals to learn and benefit from advanced prosthetic technology. This line of research may also play a role in helping to overcome locomotor impairments such as balance control and prox- imal joint compensations that persist in spite of advances in and application of prosthetic technology. Despite the remaining questions, the existing research that has contributed to our understanding of motor learning provides a foundation upon which rehabilitation protocols for individuals with lower limb loss can be based until the time that further clinical research is completed.

\section{ACKNOWLEDGMENTS}

\section{Author Contributions:}

Article concept and design: A. Sawers, D. Kartin.

Drafting of manuscript: A. Sawers, M. E. Hahn, V. E. Kelly,

J. M. Czerniecki, D. Kartin.

Critical revisions of manuscript: A. Sawers, M. E. Hahn, V. E. Kelly, J. M. Czerniecki, D. Kartin.

Financial Disclosures: The authors have declared that no competing interests exist.

Funding/Support: This material was based on work supported by a Center of Excellence grant (A4883C) from the Department of Veterans Affairs, Rehabilitation Research and Development.

Additional Contributions: Andrew Sawers is now with The Wallace H. Coulter Department of Biomedical Engineering, Emory University and the Georgia Institute of Technology, Atlanta, Georgia. Michael E. Hahn is now with the Department of Physiology, University of Oregon, Eugene, Oregon.

\section{REFERENCES}

1. Carr JH, Shepherd RB. Movement science: foundations for physical therapy in rehabilitation. 2nd ed. Gaithersburg (MD): Aspen Publishers; 2000.

2. Levin MF, Kleim JA, Wolf SL. What do motor "recovery" and "compensation" mean in patients following stroke? Neurorehabil Neural Repair. 2009;23(4):313-19. [PMID:19118128] http://dx.doi.org/10.1177/1545968308328727

3. Krakauer JW. Motor learning: its relevance to stroke recovery and neurorehabilitation. Curr Opin Neurol. 2006;19(1): 84-90. [PMID:16415682] http://dx.doi.org/10.1097/01.wco.0000200544.29915.cc

4. Martin TA, Keating JG, Goodkin HP, Bastian AJ, Thach WT. Throwing while looking through prisms. II. Specificity and storage of multiple gaze-throw calibrations. Brain. 1996;119(Pt 4):1199-1211. [PMID:8813283] http://dx.doi.org/10.1093/brain/119.4.1199

5. Krakauer JW, Shadmehr R. Consolidation of motor memory. Trends Neurosci. 2006;29(1):58-64.

[PMID:16290273] http://dx.doi.org/10.1016/j.tins.2005.10.003 
6. Muellbacher W, Ziemann U, Wissel J, Dang N, Kofler M, Facchini S, Boroojerdi B, Poewe W, Hallett M. Early consolidation in human primary motor cortex. Nature. 2002; 415(6872):640-44. [PMID:11807497] http://dx.doi.org/10.1038/nature712

7. Gold JI, Shadlen MN. The neural basis of decision making. Annu Rev Neurosci. 2007;30:535-74. [PMID:17600525] http://dx.doi.org/10.1146/annurev.neuro.29.051605.113038

8. Schmidt RA, Wrisberg CA. Motor learning and performance. 3rd ed. Champaign (IL): Human Kinetics; 2004.

9. Newell KM. Motor skill acquisition. Annu Rev Psychol. 1991;42:213-37. [PMID:2018394] http://dx.doi.org/10.1146/annurev.ps.42.020191.001241

10. Seidler RD. Neural correlates of motor learning, transfer of learning, and learning to learn. Exerc Sport Sci Rev. 2010; 38(1):3-9. [PMID:20016293] http://dx.doi.org/10.1097/JES.0b013e3181c5cce7

11. Bigelow K, Geil M, Foucher K, Requejo P, Ferris DP, Long J. Goal-directed design in rehabilitation device development and prescription. Delaware Biomechanics Priorities Conference. Newark (DE): University of Delaware; 2011.

12. Miller WC, Speechley M, Deathe B. The prevalence and risk factors of falling and fear of falling among lower extremity amputees. Arch Phys Med Rehabil. 2001;82(8): 1031-37. [PMID:11494181] http://dx.doi.org/10.1053/apmr.2001.24295

13. Prinsen EC, Nederhand MJ, Rietman JS. Adaptation strategies of the lower extremities of patients with a transtibial or transfemoral amputation during level walking: a systematic review. Arch Phys Med Rehabil. 2011;92(8):1311-25. [PMID:21714957] http://dx.doi.org/10.1016/j.apmr.2011.01.017

14. Hofstad CJ, Weerdesteyn V, van der Linde H, Nienhuis B, Geurts AC, Duysens J. Evidence for bilaterally delayed and decreased obstacle avoidance responses while walking with a lower limb prosthesis. Clin Neurophysiol. 2009; 120(5):1009-15. [PMID:19362881] http://dx.doi.org/10.1016/j.clinph.2009.03.003

15. Ramstrand N, Nilsson KA. A comparison of foot placement strategies of transtibial amputees and able-bodied subjects during stair ambulation. Prosthet Orthot Int. 2009; 33(4):348-55. [PMID:19961296] http://dx.doi.org/10.3109/03093640903074891

16. Poole JL. Application of motor learning principles in occupational therapy. Am J Occup Ther. 1991;45(6):531-37. [PMID:2063942] http://dx.doi.org/10.5014/ajot.45.6.531

17. Winstein CJ. Knowledge of results and motor learningimplications for physical therapy. Phys Ther. 1991;71(2): 140-49. [PMID:1989009]

18. Donaghey CL, McMillan TM, O’Neill B. Errorless learning is superior to trial and error when learning a practical skill in rehabilitation: a randomized controlled trial. Clin Rehabil. 2010;24(3):195-201. [PMID:20156980]

http://dx.doi.org/10.1177/0269215509353270

19. Dingwell JB, Davis BL, Frazier DM. Use of an instrumented treadmill for real-time gait symmetry evaluation and feedback in normal and trans-tibial amputee subjects. Prosthet Orthot Int. 1996;20(2):101-10. [PMID:8876003]

20. Weeks DL, Anderson DI, Wallace SA. The role of variability in practice structure when learning to use an upperextremity prosthesis. J Prosthet Orthot. 2003;15(3):84-92.

21. Matjaĉić Z, Burger H. Dynamic balance training during standing in people with trans-tibial amputation: a pilot study. Prosthet Orthot Int. 2003;27(3):214-20.

[PMID:14727702]

http://dx.doi.org/10.1080/03093640308726684

22. Mensch G. Physiotherapy following through-knee amputation. Prosthet Orthot Int. 1983;7(2):79-87. [PMID:6622238]

23. Smith DG, Michael JW, Bowker JH; American Academy of Orthopaedic Surgeons. Atlas of amputations and limb deficiencies: surgical, prosthetic, and rehabilitation principles. Rosemont (IL): American Academy of Orthopaedic Surgeons; 2004.

24. Sjödahl C, Jarnlo GB, Söderberg B, Persson BM. Kinematic and kinetic gait analysis in the sagittal plane of trans-femoral amputees before and after special gait re-education. Prosthet Orthot Int. 2002;26(2):101-12. [PMID:12227444] http://dx.doi.org/10.1080/03093640208726632

25. Donachy JE, Brannon KD, Hughes LS, Seahorn J, Crutcher TT, Christian EL. Strength and endurance training of an individual with left upper and lower limb amputations. Disabil Rehabil. 2004;26(8):495-99. [PMID:15204472] http://dx.doi.org/10.1080/09638280410001663067

26. Kegel B, Burgess EM, Starr TW, Daly WK. Effects of isometric muscle training on residual limb volume, strength, and gait of below-knee amputees. Phys Ther. 1981;61(10): 1419-26. [PMID:7280021]

27. Pitetti KH, Snell PG, Stray-Gundersen J, Gottschalk FA. Aerobic training exercises for individuals who had amputation of the lower limb. J Bone Joint Surg Am. 1987;69(6): 914-21. [PMID:3597505]

28. Rau B, Bonvin F, de Bie R. Short-term effect of physiotherapy rehabilitation on functional performance of lower limb amputees. Prosthet Orthot Int. 2007;31(3):258-70. [PMID:17979011] http://dx.doi.org/10.1080/03093640600994615

29. Yiğiter K, Sener G, Erbahçeci F, Bayar K, Ulger OG, Akdoğan S. A comparison of traditional prosthetic training versus proprioceptive neuromuscular facilitation resistive gait training with trans-femoral amputees. Prosthet Orthot Int. 2002;26(3):213-17. [PMID:12562068] http://dx.doi.org/10.1080/03093640208726650 
30. Klute GK, Kantor C, Darrouzet C, Wild H, Wilkinson S, Iveljic S, Creasey G. Lower-limb amputee needs assessment using multistakeholder focus-group approach. J Rehabil Res Dev. 2009;46(3):293-304. [PMID:19675983] http://dx.doi.org/10.1682/JRRD.2008.02.0031

31. Grill WM. NAKFI smart prosthetics: exploring assistive devices for the body and mind. Expert Rev Med Devices. 2007;4(2):107-8. [PMID:17359216] http://dx.doi.org/10.1586/17434440.4.2.107

32. Crossman ER. A theory of the acquisition of speed skill. Ergonomics. 1959;2:153-66. http://dx.doi.org/10.1080/00140135908930419

33. Snoddy GS. Learning and stability: A psychophysical analysis of a case of motor learning with clinical applications. J Appl Psychol. 1926;10:1-36. http://dx.doi.org/10.1037/h0075814

34. Schmidt R, Lee D. Motor control and learning: a behavioral emphasis. Champaign (IL): Human Kinetics; 2005.

35. Kyllo LB, Landers DM. Goal setting in sport and exercise: A research synthesis to resolve the controversy. J Sport Exerc Psychol. 1995;17(2):117-37.

36. Locke EA, Latham GP. The application of goal setting to sports. J Sport Exerc Psychol. 1985;7(3):205-22.

37. Rosewilliam S, Roskell CA, Pandyan AD. A systematic review and synthesis of the quantitative and qualitative evidence behind patient-centred goal setting in stroke rehabilitation. Clin Rehabil. 2011;25(6):501-14.

[PMID:21441308] http://dx.doi.org/10.1177/0269215510394467

38. Playford ED, Siegert R, Levack W, Freeman J. Areas of consensus and controversy about goal setting in rehabilitation: a conference report. Clin Rehabil. 2009;23(4):334-44. [PMID:19449469] http://dx.doi.org/10.1177/0269215509103506

39. McCullagh P, Weiss M. Modelling: considerations for motor skill performance and psychological responses. In: Singer R, Hausenblas H, Janelle C, editors. Handbook of sport psychology. 2nd ed. New York (NY): Wiley; 2001. p. 205-38.

40. Feltz D, Landers D, Becker B. A revised meta-analysis of the mental practice literature on motor skill learning. In: Druckman D, Swets J, editors. Enhancing human performance: issues, theories and techniques. Washington (DC): National Academy Press; 1988. p. 1-65.

41. Gray JT, Neisser U, Shapiro BA, Kouns S. Observational learning of ballet sequences: The role of kinematic information. Ecol Psychol. 1991;3(2):121-34. http://dx.doi.org/10.1207/s15326969eco0302_4

42. Custers EJ, Regehr G, McCulloch W, Peniston C, Reznick $\mathrm{R}$. The effects of modeling on learning a simple surgical procedure: see one, do one or see many, do one? Adv Health Sci Educ Theory Pract. 1999;4(2):123-43.

\section{[PMID:12386425]}

http://dx.doi.org/10.1023/A:1009763210212

43. McCullagh P, Meyer KN. Learning versus correct models: influence of model type on the learning of a free-weight squat lift. Res Q Exerc Sport. 1997;68(1):56-61. [PMID:9094763]

44. Pollock BJ, Lee TD. Effects of the model's skill level on observational motor learning. Res Q Exerc Sport. 1992; 63(1):25-29. [PMID:1574658]

45. Grèzes J, Decety J. Functional anatomy of execution, mental simulation, observation, and verb generation of actions: a meta-analysis. Hum Brain Mapp. 2001;12(1):1-19.

[PMID:11198101]

http://dx.doi.org/10.1002/10970193(200101)12:1<1::AID-HBM10>3.0.CO;2-V

46. Jeannerod M. The representing brain: Neural correlates of motor intention and imagery. Behav Brain Sci. 1994;17(2): 187-202. http://dx.doi.org/10.1017/S0140525X00034026

47. Decety J. Do imagined and executed actions share the same neural substrate? Brain Res Cogn Brain Res. 1996; 3(2):87-93. [PMID:8713549] http://dx.doi.org/10.1016/0926-6410(95)00033-X

48. Bird EI. EMG quantification of mental rehearsal. Percept Mot Skills. 1984;59(3):899-906.

http://dx.doi.org/10.2466/pms.1984.59.3.899

49. Malouin F, Richards CL, Durand A, Descent M, Poiré D, Frémont P, Pelet S, Gresset J, Doyon J. Effects of practice, visual loss, limb amputation, and disuse on motor imagery vividness. Neurorehabil Neural Repair. 2009;23(5):449-63. [PMID:19182047] http://dx.doi.org/10.1177/1545968308328733

50. Roux FE, Ibarrola D, Lazorthes Y, Berry I. Virtual movements activate primary sensorimotor areas in amputees: report of three cases. Neurosurgery. 2001;49(3):736-42. [PMID:11523688]

51. Féry YA. Differentiating visual and kinesthetic imagery in mental practice. Can J Exp Psychol. 2003;57(1):1-10. [PMID:12674365] http://dx.doi.org/10.1037/h0087408

52. Malouin F, Richards CL. Mental practice for relearning locomotor skills. Phys Ther. 2010;90(2):240-51. [PMID:20022993] http://dx.doi.org/10.2522/ptj.20090029

53. Dickstein R, Deutsch JE. Motor imagery in physical therapist practice. Phys Ther. 2007;87(7):942-53. [PMID: 17472948] http://dx.doi.org/10.2522/ptj.20060331

54. Shea CH, Wright DL, Wulf G, Whitacre C. Physical and observational practice afford unique learning opportunities. J Mot Behav. 2000;32(1):27-36. [PMID:11008269] http://dx.doi.org/10.1080/00222890009601357 
55. Weeks DL, Anderson LP. The interaction of observational learning with overt practice: effects on motor skill learning. Acta Psychol (Amst). 2000;104(2):259-71.

[PMID:10900708]

http://dx.doi.org/10.1016/S0001-6918(00)00039-1

56. Gentili R, Han CE, Schweighofer N, Papaxanthis C. Motor learning without doing: trial-by-trial improvement in motor performance during mental training. J Neurophysiol. 2010; 104(2):774-83. [PMID:20538766] http://dx.doi.org/10.1152/jn.00257.2010

57. Hird JS, Landers DM, Thomas JR, Horan JJ. Physical practice is superior to mental practice in enhancing cognitive and motor task performance. J Sport Exerc Psychol. 1991; 13(3):281-93.

58. Sanchez-Ku ML, Arthur W Jr. A dyadic protocol for training complex skills: a replication using female participants. Hum Factors. 2000;42(3):512-20. [PMID:11132811] http://dx.doi.org/10.1518/001872000779698169

59. Shea $\mathrm{CH}$, Wulf $\mathrm{G}$, Whitacre $\mathrm{C}$. Enhancing training efficiency and effectiveness through the use of dyad training. J Mot Behav. 1999;31(2):119-25. [PMID:11177626] http://dx.doi.org/10.1080/00222899909600983

60. Shebilskem WL, Regian JW, Arthur W Jr, Jordan JA. A dyadic protocol for training complex skills. Hum Factors. 1992;34(3):369-74.

61. Deakin JM, Proteau L. The role of scheduling in learning through observation. J Mot Behav. 2000;32(3):268-76. [PMID:10975274] http://dx.doi.org/10.1080/00222890009601377

62. Donovan JJ, Radosevich DJ. A meta-analytic review of the distribution of practice effect: now you see it, now you don’t. J Appl Psychol. 1999;84(5):795-805. http://dx.doi.org/10.1037/0021-9010.84.5.795

63. Bourne LE Jr, Archer EJ. Time continuously on target as a function of distribution of practice. J Exp Psychol. 1956; 51(1):25-33. [PMID:13286436] http://dx.doi.org/10.1037/h0039887

64. Shea CH, Lai Q, Black C, Park JH. Spacing practice sessions across days benefits the learning of motor skills. Hum Mov Sci. 2000;19(5):737-60. http://dx.doi.org/10.1016/S0167-9457(00)00021-X

65. Lee TD, Genovese ED. Distribution of practice in motor skill acquisition: different effects for discrete and continuous tasks. Res Q Exerc Sport. 1989;60(1):59-65.

[PMID:2489826]

66. Roller CA, Cohen HS, Kimball KT, Bloomberg JJ. Variable practice with lenses improves visuo-motor plasticity. Brain Res Cogn Brain Res. 2001;12(2):341-52. [PMID:11587905] http://dx.doi.org/10.1016/S0926-6410(01)00077-5
67. Shea CH, Kohl RM. Composition of practice: influence on the retention of motor skills. Res Q Exerc Sport. 1991; 62(2):187-95. [PMID:1925042]

68. Catalano JF, Kleiner BM. Distant transfer in coincident timing as a function of variability of practice. Percept Mot Skills. 1984;58(3):851-56. http://dx.doi.org/10.2466/pms.1984.58.3.851

69. Brady F. Contextual interference: a meta-analytic study. Percept Mot Skills. 2004;99(1):116-26. [PMID:15446636] http://dx.doi.org/10.2466/pms.99.1.116-126

70. Shea JB, Morgan RL. Contextual interference effects on the acquisition, retention, and transfer of a motor skill. J Exp Psychol Hum Learn. 1979;5(2):179-87. http://dx.doi.org/10.1037/0278-7393.5.2.179

71. Mané AM, Adams JA, Donchin E. Adaptive and partwhole training in the acquisition of a complex perceptualmotor skill. Acta Psychol (Amst). 1989;71(1-3):179-96. http://dx.doi.org/10.1016/0001-6918(89)90008-5

72. Briggs GE, Waters LK. Training and transfer as a function of component interaction. J Exp Psychol. 1958;56(6):492-500. [PMID:13611174] http://dx.doi.org/10.1037/h0044022

73. Domingo A, Ferris DP. Effects of physical guidance on short-term learning of walking on a narrow beam. Gait Posture. 2009;30(4):464-68. [PMID:19674900] http://dx.doi.org/10.1016/j.gaitpost.2009.07.114

74. Sidaway B, Ahn S, Boldeau P, Griffin S, Noyes B, Pelletier $\mathrm{K}$. A comparison of manual guidance and knowledge of results in the learning of a weight-bearing skill. J Neurol Phys Ther. 2008;32(1):32-38. [PMID:18463553]

75. Wulf G, Toole T. Physical assistance devices in complex motor skill learning: benefits of a self-controlled practice schedule. Res Q Exerc Sport. 1999;70(3):265-72. [PMID:10522284]

76. Pauley T, Devlin M, Heslin K. Falls sustained during inpatient rehabilitation after lower limb amputation: prevalence and predictors. Am J Phys Med Rehabil. 2006;85(6):521-35. [PMID:16715022] http://dx.doi.org/10.1097/01.phm.0000219119.58965.8c

77. Wulf G. Attention and motor skill learning. Champaign (IL): Human Kinetics; 2007.

78. Wulf G, McConnel N, Gärtner M, Schwarz A. Enhancing the learning of sport skills through external-focus feedback. J Mot Behav. 2002;34(2):171-82. [PMID:12057890] http://dx.doi.org/10.1080/00222890209601939

79. Wulf G, Su J. An external focus of attention enhances golf shot accuracy in beginners and experts. Res Q Exerc Sport. 2007;78(4):384-89. [PMID:17941543] http://dx.doi.org/10.5641/193250307X13082505158336

80. Zachry T, Wulf G, Mercer J, Bezodis N. Increased movement accuracy and reduced EMG activity as the result of adopting an external focus of attention. Brain Res Bull. 
2005;67(4):304-9. [PMID:16182938]

http://dx.doi.org/10.1016/j.brainresbull.2005.06.035

81. Wulf G, Höß M, Prinz W. Instructions for motor learning: differential effects of internal versus external focus of attention. J Mot Behav. 1998;30(2):169-79.

[PMID:20037032]

http://dx.doi.org/10.1080/00222899809601334

82. Wulf G, McNevin N, Shea CH. The automaticity of complex motor skill learning as a function of attentional focus. Q J Exp Psychol A. 2001;54(4):1143-54. [PMID:11765737]

83. Bilodeau EA, Bilodeau IM, Schumsky DA. Some effects of introducing and withdrawing knowledge of results early and late in practice. J Exp Psychol. 1959;58:142-44.

[PMID:13800728] http://dx.doi.org/10.1037/h0040262

84. Magill RA. Modeling and verbal feedback influences on skill learning. Int J Sport Psychol. 1993;24(4):358-69.

85. Winstein CJ, Schmidt RA. Reduced frequency of knowledge of results enhances motor skill learning. J Exp Psychol Learn Mem Cogn. 1990;16(4):677-91. http://dx.doi.org/10.1037/0278-7393.16.4.677

86. Wulf G, Shea CH, Matschiner S. Frequent feedback enhances complex motor skill learning. J Mot Behav. 1998; 30(2):180-92. [PMID:20037033] http://dx.doi.org/10.1080/00222899809601335

87. Swinnen SP, Nicholson DE, Schmidt RA, Shapiro DC. Information feedback for skill acquisition: Instantaneous knowledge of results degrades learning. J Exp Psychol Learn Mem Cogn. 1990;16(4):706-16. http://dx.doi.org/10.1037/0278-7393.16.4.706

88. Guadagnoli MA, Dornier LA, Tandy RD. Optimal length for summary knowledge of results: the influence of task- related experience and complexity. Res Q Exerc Sport. 1996;67(2):239-48. [PMID:8836005]

89. Lavery JJ, Suddon FH. Retention of simple motor skills as a function of the number of trials by which $\mathrm{KR}$ is delayed. Percept Mot Skills. 1962;15:231-37. [PMID:14462931] http://dx.doi.org/10.2466/pms.1962.15.1.231

90. Yao WX, Fischman MG, Wang YT. Motor skill acquisition and retention as a function of average feedback, summary feedback, and performance variability. J Mot Behav. 1994; 26(3):273-82. [PMID:15757843] http://dx.doi.org/10.1080/00222895.1994.9941683

91. Patla AE, Shumway-Cook A. Dimensions of mobility: Defining the complexity and difficulty associated with community mobility. J Aging Phys Act. 1999;7:7-19.

92. Patla AE. Understanding the control of human locomotion: a 'Janus' perspective. In: Patla AE, editor. Adaptability of human gait: implications for the control of locomotion. Amsterdam (the Netherlands): Elsevier; 1991. p. 441-52.

Submitted for publication December 12, 2011. Accepted in revised form May 2, 2012.

This article and any supplementary material should be cited as follows:

Sawers A, Hahn ME, Kelly VE, Czerniecki JM, Kartin D. Beyond componentry: How principles of motor learning can enhance locomotor rehabilitation of individuals with lower limb loss-A review. J Rehabil Res Dev. 2012; 49(10):1431-42.

http://dx.doi.org/10.1682/JRRD.2011.12.0235

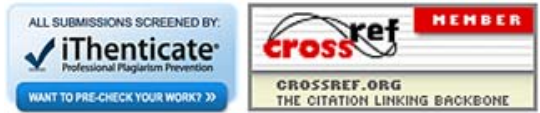


